\title{
Detergents and surfactants: a brief review
}

\begin{abstract}
Since ancient times, human being has tried to find a way for cleaning clothes, house floor, agricultural tools and so on. In the present work, we briefly describe the history of detergents and the way that they developed. In addition we write about the components of powdered and liquid detergents and the components we produce and use in our detergents. All of the surfactants that are used in industrial applications are described and their synthesis is discussed.
\end{abstract}

Keywords: detergent, surfactant, LABS, SLES
Volume 3 Issue 3 - 2019

\author{
Babak Babajanzadeh, Saied Sherizadeh, Hasan \\ Ranji \\ Science and Engineering Complex, Padideh Shimi Gharb \\ Industrial Group, Iran
}

Correspondence: Hasan Ranji, Padideh Shimi Gharb Industrial Group, Science and Engineering Complex, R\&D lab, Tehran, Iran, Tel+9892 I I 49083, Email hasanranjil989@gmail.com

Received: May 26, 2019 | Published: June 04, 2019

\section{Introduction}

The use of laundry detergents based on synthetic ingredients is not an old innovation. Since ancient times until World War I, people for washing their clothes used soaps that were produced by saponifying fats and oils into fatty acid salts. In 1931, for the first time, Dreft powder introduced to the world as a synthetic detergent in the US. In 1946, Tide came to be known as a new detergent by $P \& G$, armed with the phosphate. In 1988, the same company produced for the first time in history of detergents, liquid detergent with color-safe bleach. For decades, powdered and liquid laundry detergents containing linear alkyl benzene sulfonates (LABS), sodium lauryl ether sulfate (SLES), sodium dodecyl sulfate (SDS), ether sulfates, and alcohol ethoxylates as surfactants, along with builders, enzymes, polymers, and possibly bleaches as additional active ingredients have been used to meet the household laundry needs. These formulations were designed to deal with different types of dirt and stains depended on water conditions at various countries and cities. ${ }^{1}$ Recently, significant efforts have been done to develop surfactants to be used in detergent industry. In commercial applications some of the surfactants such as $\alpha$-sulfomethyl esters and alkyl polyglucosides (APGs) are known as newer materials. Some of the other materials, such as ethoxylated amines, alkanolamides, betaines, alkyldiphenyl, and oxide disulfonates, have been used for many years routinely in other industries. One of the mostly used surfactants which have been used in powdered detergent industry is believed to be linear alkylbenzene sulfonate known as LAS. This surfactant is an inexpensive and accessible ingredient that is effective on dirt but less so on greasy or oily stains. Hence, still, searching for raw materials with low cost, higher yields and most importantly searching for green methodologies in detergent industry is of prime importance.

According to a report obtained by Henkel in 1989, household detergent formulations vary in the U.S., Japan and Western Europe (Table 1). In 1967, Augustin, studied about an aqueous polyoxyalkylene ether detergent-inorganic builder concentrates. According to this patent it was determined that water-soluble alkyl sulfates such as sodium lauryl ether sulfate (SLES), sodium palmityl sulfate, sodium octadecyl sulfate, SDS and sodium octyl sulfate in small amounts can inhibit the precipitation or salting-out of polyoxyalkylene glycol ethers from aqueous concentrates with inorganic builders. ${ }^{2}$ In 1981 , O'brien and Benjamin reported the liquid detergent compositions that provide superior removal of protein and carbohydrate-based soils in a hand dishwashing process. Their product composition was as follows: (a) an anionic surfactant $15 \%-50 \%$ by weight, (b) an amide $2.5 \%-10 \%$ by weight, (c) a reducing agent comprising salts which are soluble in water obtained by reductive sulfur oxygen acids and acids which are reductive and obtained from phosphorus, inorganic nitrogen compounds which are reductive, stannites and mixtures $2 \%-25 \%$ by weight, (d) a protein denaturant chosen from the group comprising urea, guanidine and its salts, thiourea, biuret, thiobiuret and the water soluble alkyl, alkylol and acyl derivatives of these materials, alkanolamines, ammonia, and mixtures 2\%-20\% by weight, and (e) $20 \%$ to $88.5 \%$ water in a $\mathrm{pH}$ of 9.5 at $20{ }^{\circ} \mathrm{C}$. Their used anionic surfactants were potassium lauryl alkyl sulfate, sodium lauryl alkyl sulfate, sodium palmityl alkyl sulfate, SDS, sodium myristyl alkyl sulfate, potassium palmityl alkyl sulfate, potassium decyl sulfate, sodium coconut alkyl sulfate, potassium coconut alkyl sulfate, potassium myristyl alkyl sulfate, magnesium dodecyl sulfate, magnesium C12-15 alkyl sulfate and mixtures of these surfactants. ${ }^{3}$

Goffinet represented a patent entitled liquid detergent compositions, in 1983. His invention was related to aqueous detergent compositions suitable for use as general purpose household cleaning compositions. In this report, he described the invention as follows: (a) a synthetic surfactant (anionic, nonionic, amphoteric or zwitterionic) or mixture of them $1 \%-20 \%$ by weight, (b) a mono-or sesquiterpene or mixture and (c) a polar solvent $(0.2 \%-10 \%$ by weight) possessing a solubility in water ranging $0.5-10 \%$ at $25^{\circ} \mathrm{C}$. They used nonionic surfactants such as polyethylene oxide obtained by alkyl phenol, the condensation product of primary or secondary aliphatic alcohols possessing 8-24 carbon atoms, and the compounds obtained by condensing ethylene oxide with a hydrophobic base formed by the condensation of propylene oxide with either propylene glycol orethylene diamine. ${ }^{4}$ In 2002, Hinton, investigated on a new detergent and studied about various compositions for the detergent. In the study, detergent comprised at least one ingredient chosen from the group comprising LABS, sodium lauryl sulphate (SLS), sodium carbonate, perfumes, low foam wetting agent, pigments and enzymes. ${ }^{5}$ It was shown that this methodology described a suitable way to produce the laundry or dishwashing detergents for household uses. Environmental impacts of detergents compositions are inevitable. Zamora and Alvarez investigated about these environmental impacts in surface sediments at the south end of the Southern California Bight (Figure 1). ${ }^{6}$ Among a variety of these components, they choose LABs to study detergents environmental impacts at the mentioned area because other pollutants whose chemical behavior is similar to that of LABs may also have the same fate. Their main purpose of this study was to investigate the extent of the impact of municipal water discharges on southern SCB sediments. According to their results, LABs were not significantly 
correlated with either the grain size $<63 \mathrm{~mm}$ or with carbon content in the sediments. They realized that this is due to mixing of different

Table I U.S., Japan and Western Europe used household detergent formulations sediment sources in the area. This investigation shows that the main part of the used detergents in the USA is LABs.

\begin{tabular}{|c|c|c|c|c|c|c|c|}
\hline \multirow[b]{3}{*}{ Component } & \multirow[b]{3}{*}{ Examples } & \multirow{2}{*}{\multicolumn{2}{|c|}{ U.S. }} & \multicolumn{4}{|c|}{ Composition, \% } \\
\hline & & & & \multicolumn{3}{|c|}{ Western Europe } & \multirow{2}{*}{$\begin{array}{l}\text { Japan } \\
\text { Without } \\
\text { builders }\end{array}$} \\
\hline & & $\begin{array}{l}\text { With } \\
\text { builders }\end{array}$ & $\begin{array}{l}\text { Without } \\
\text { builders }\end{array}$ & $\begin{array}{l}\text { With } \\
\text { builders }\end{array}$ & $\begin{array}{l}\text { Without } \\
\text { builders }\end{array}$ & $\begin{array}{l}\text { With } \\
\text { builders }\end{array}$ & \\
\hline \multicolumn{8}{|c|}{ Heavy duty-powdered detergents } \\
\hline \multirow[t]{4}{*}{ Anionic surfactants } & Alkybenzene sulfonates & $0-15 \%$ & $0-20 \%$ & $5-10 \%$ & $5-10 \%$ & $5-15 \%$ & $5-15 \%$ \\
\hline & Fatty alcohol sulfonates & - & - & $1-3$ & - & $0-10$ & $0-10$ \\
\hline & Fatty alcohol ether sulfonates & $0-12$ & $0-10$ & - & - & - & - \\
\hline & Alpha-olefin sulfonates & - & - & - & - & $0-15$ & $0-15$ \\
\hline $\begin{array}{l}\text { nonionic } \\
\text { surfactants }\end{array}$ & $\begin{array}{l}\text { Alkyl and nonylphenyl } \\
\text { ploy(ethylene glycol) ethers }\end{array}$ & $0-17$ & $0-17$ & II-Mar & $3-6$ & $0-2$ & $0-2$ \\
\hline $\begin{array}{l}\text { Soda- controlling } \\
\text { agents }\end{array}$ & Soaps, silicon, oils, paraffin & $0-1.0$ & $0-0.6$ & $0.1-3.5$ & $0.1-3.5$ & $1-3$ & $1-3$ \\
\hline Foam boosters & $\begin{array}{l}\text { Fatty acid monoethanal } \\
\text { amides }\end{array}$ & - & - & $0-2$ & - & - & - \\
\hline $\begin{array}{l}\text { Chelators } \\
\text { (Bullders) }\end{array}$ & Sodium tripolyphosphate & $23-55$ & - & $20-40$ & - & $10-20$ & - \\
\hline Ion exchangers & $\begin{array}{l}\text { Zeolite } 4 \mathrm{~A} \text {, poly(acrylic } \\
\text { acids) }\end{array}$ & - & $0-45$ & $2-20$ & $20-30$ & $0-2$ & $20-O c t$ \\
\hline Alkalles & Sodium carbonate & 3- 22 & $10-35$ & $0-15$ & $5-10$ & $5-20$ & $5-20$ \\
\hline Cobullders & $\begin{array}{l}\text { Sodium citrate, Sodium } \\
\text { nitrilotrlacetate }\end{array}$ & - & - & $0-4$ & $0-4$ & - & - \\
\hline Bleaching agents & sodium perborate & $0-5$ & $0-5$ & $10-25$ & $20-25$ & $0-5$ & $0-5$ \\
\hline Bleach activvators & Tetraacetylethylenediamine & - & - & $0-5$ & $0-2$ & - & - \\
\hline Bleach stabilizers & Ethylenediaminetetraacetate & - & - & $0.2-0.5$ & $0.2-0.5$ & - & - \\
\hline Fabric softners & $\begin{array}{l}\text { Quaternary ammonium } \\
\text { compounds }\end{array}$ & $0-5$ & $0-5$ & - & - & - & $0-5$ \\
\hline $\begin{array}{l}\text { Antlredeposition } \\
\text { agents }\end{array}$ & Cellulose ethers & $0-0.5$ & $0-0.5$ & $0.5-1.5$ & $0.5-15$ & $0-2$ & $0-2$ \\
\hline Enzymes & Proteases, Amylases & $0-2.5$ & $0-2.5$ & $0.3-0.6$ & $0.3-09$ & $0-05$ & $0-05$ \\
\hline Optical brighteners & Stibene derivatives & $0.05-0.25$ & $0.05-025$ & $0.1-0.3$ & $0.1-0.3$ & $0.1-0.6$ & $0.1-0.8$ \\
\hline $\begin{array}{l}\text { Anrticorroaion } \\
\text { agents }\end{array}$ & Sodium silicate & 10 & 025 & $2-6$ & 2- 8 & $5-15$ & $5-15$ \\
\hline Fragrances & & $\mathrm{a}$ & $\mathrm{a}$ & $\mathrm{a}$ & $\mathrm{a}$ & $\mathrm{a}$ & $\mathrm{a}$ \\
\hline $\begin{array}{l}\text { Dyes and blueing } \\
\text { agents }\end{array}$ & & $\mathrm{a}$ & a & $\mathrm{a}$ & $\mathrm{a}$ & $\mathrm{a}$ & $\mathrm{a}$ \\
\hline Formulation aids & & $0-1.0$ & $0-1.0$ & - & - & - & - \\
\hline Filters and water & Sodium sulfonate & Balance & Balance & Balance & Balance & Balance & Balance \\
\hline \multicolumn{8}{|c|}{ Heavy duty liquid detergents } \\
\hline \multirow[t]{3}{*}{ Anionic surfactants } & Alkybertzene salfonates & $5-17$ & $0-10$ & $5-7$ & $10-15$ & $5-15$ & - \\
\hline & Fatty alcohol ether surfates & $0-15$ & $0-12$ & - & - & $5-10$ & $15-25$ \\
\hline & Soaps & $5-17$ & $0-10$ & $5-7$ & $10-15$ & $5-15$ & - \\
\hline
\end{tabular}


Composition, \%

\begin{tabular}{|c|c|c|c|c|c|c|c|}
\hline \multirow[b]{2}{*}{ Component } & \multirow[b]{2}{*}{ Examples } & \multicolumn{2}{|l|}{ U.S. } & \multicolumn{3}{|c|}{ Western Europe } & \multirow{2}{*}{$\begin{array}{l}\text { Japan } \\
\text { Without } \\
\text { builders }\end{array}$} \\
\hline & & $\begin{array}{l}\text { With } \\
\text { builders }\end{array}$ & $\begin{array}{l}\text { Without } \\
\text { builders }\end{array}$ & $\begin{array}{l}\text { With } \\
\text { builders }\end{array}$ & $\begin{array}{l}\text { Without } \\
\text { builders }\end{array}$ & $\begin{array}{l}\text { With } \\
\text { builders }\end{array}$ & \\
\hline \multicolumn{8}{|c|}{ Heavy duty-powdered detergents } \\
\hline $\begin{array}{l}\text { Nonionic } \\
\text { surfactants }\end{array}$ & $\begin{array}{l}\text { Alkyl poly(ethylene glycol) } \\
\text { ethers }\end{array}$ & $0-14$ & - & - & $10-15$ & $10-20$ & - \\
\hline $\begin{array}{l}\text { Sude- controlling } \\
\text { agents }\end{array}$ & Soaps & 5- 11 & $15-35$ & 2- 5 & $10-15$ & $4-10$ & $10-1$ \\
\hline Foam boosters & Fatty acids alkanoiamides & - & - & $0-2$ & 3- 5 & - & - \\
\hline Enzymes & Proteases & $0-16$ & $0-23$ & $0.3-0.5$ & $0.6-0.5$ & $0.1-0.5$ & $0.2-0.8$ \\
\hline \multirow[t]{2}{*}{ Bullders } & $\begin{array}{l}\text { Potassium diphosphate, } \\
\text { sodium Tripolyphosphate }\end{array}$ & - & - & $20-25$ & - & - & - \\
\hline & $\begin{array}{l}\text { Sodium citrate, sodium } \\
\text { silicate }\end{array}$ & 6- 12 & - & - & $0-3$ & 3- 7 & - \\
\hline Formulation aids & $\begin{array}{l}\text { Xylene sulfonates, ethanol, } \\
\text { propylene glycol }\end{array}$ & $7-14$ & 5- 12 & $3-6$ & $6-12$ & $10-15$ & $5-15$ \\
\hline Optical brighteners & Stilbene derivatives & $0.1-0.25$ & $0.1-0.25$ & $0.15-0.25$ & $0.15-0.25$ & $0.1-0.3$ & $0.1-0.3$ \\
\hline Stabilizers & Triethanolamine & - & - & - & $1-3$ & I- 3 & I- 5 \\
\hline Fabric softeners & Quaternary ammonium salts & $0-2$ & 0 & - & - & - & - \\
\hline Fragrances & & $\mathrm{a}$ & a & a & $\mathrm{a}$ & $\mathrm{a}$ & a \\
\hline Dyes & & a & a & a & $\mathrm{a}$ & $\mathrm{a}$ & $\mathrm{a}$ \\
\hline Water & & Balance & Balance & Balance & Balance & Balance & Balance \\
\hline
\end{tabular}

Sandhu et al. ${ }^{7}$ in 2018 reported a process to modify the internal structure of detergent surfactant agglomerates using electromagnetic heating to produce a lower bulk density final product. ${ }^{7}$ They heated agglomerates in a $1.8 \mathrm{KW}$ microwave waveguide heating applicator operating at license-free ISM frequency band of $2450 \mathrm{MHz}$. They observed that the density of the agglomerates reduced significantly at the time of exposing to high power electromagnetic fields (Figure 2). In addition, they concluded that by applying microwave heating, the porosity of the materials can be increased significantly without affecting its chemical properties. In our company we use LABS, but why it seems to be necessary to use it for producing detergents? LABSs are combined with other surfactants such as SLES in our detergent formulation to give desired cost/performance. In addition to cost performance, other advantages such as the ease of spray drying if a powdered product is being made could be mentioned (Figure 3 ). For the first time, the Friedel-Crafts alkylation of benzene with propylene tetramer was used to obtain the first alkylbenzene sulfonates as shown in Figure $4 .{ }^{8}$ Halligudi et al. ${ }^{8}$ in 2006, introduced a method for the synthesis of LAB. They used AlMCM-41/Beta zeolite composite as a catalyst for the synthesis of $\mathrm{LAB}$ via alkylation of benzene with $\mathrm{C}_{10-14}$ linear alkenes. ${ }^{9}$ In other words; they investigated the liquid-phase alkylation of benzene possessing long-chain olefins like 1-decene, 1-octene and 1-dodecene over AlMCM-41/Beta zeolite composite material as catalyst Figure 5. In addition, they studied the activity of the composite material in alkylation of benzene with different olefins Table2.
In recent decades, synthetic surfactants have been used significantly in different fields of application. It is noteworthy that almost one half of these surfactants are used in domestic cleaning detergents. Synthetic surfactants have unique properties such as reduction of interracial tension and formation of micelles which is because of their structure. In general, their molecules consist of a polar head group, which interacts favorably with water and a nonpolar hydrocarbon tail, which is not easily dissolved in water which in turn gives rise to amphiphilic properties of these compounds. Synthetic surfactants hydrophobicity is because of a long chain aliphatic hydrocarbon that they consist. Surfactants generally are classified into 4 categories: noncharged, amphoteric, cationic or anionic, according to the charge of their headgroup (Figure 6). Surfactants are important in terms of environmental aspect because, after use, a major portion is disposed into wastewater and will eventually find a way into natural fresh waters. There have been many investigations and facilities for wastewater treatment which are effective in largely reducing the concentrations of surfactants. Accordingly, the companies that use these compounds must consider the treatment processes. ${ }^{10}$

\section{Anionic surfactants}

One of the surfactants that mostly are used in laundry detergents is anionic surfactants because of their excellent work to remove dirt, clay, and some oily stains. To start working, these surfactants are needed to be ionized. When anionic surfactants are added to water, they start to be ionized and obtain a negative charge. Dirt, clay, and 
some oily stains which are positively charged particles bind to the negatively charged surfactants. They are significantly effective in removing particulate soils. Anionic surfactants generally give higher levels of foam compared to the other classes of surfactants. SLES (Figure7), sulfonic acid salts, alcohol sulfates, alkylbenzene sulfonates, phosphoric acid esters, and carboxylic acid salts are some examples of anionic surfactants. ${ }^{11}$

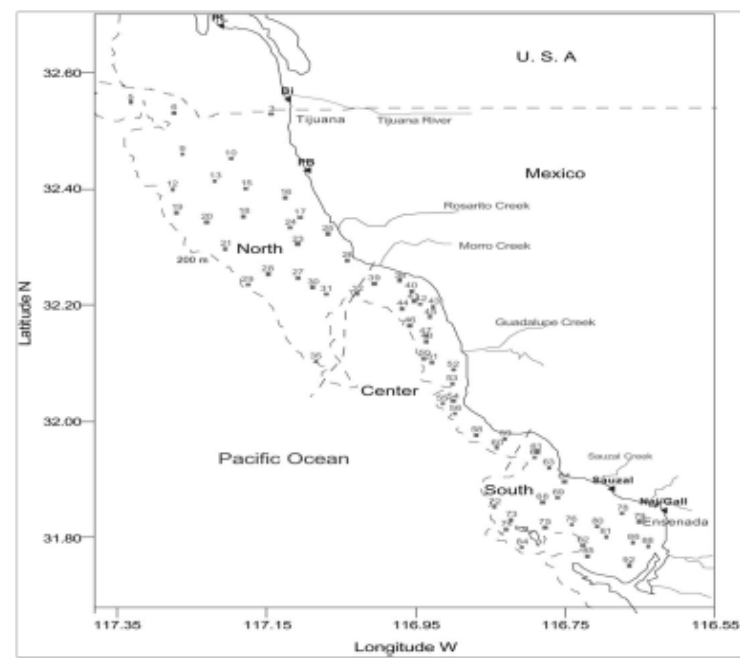

Figure I The places from which samples of the experiment were gathered.

\section{a}

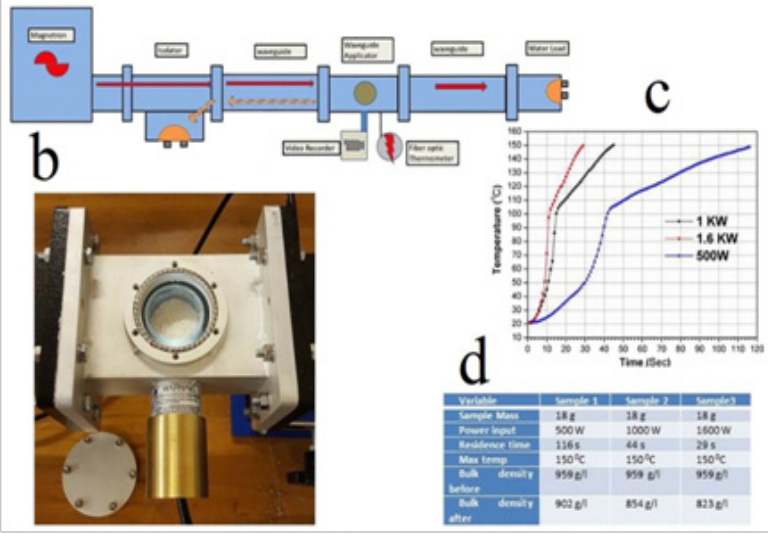

Figure 2 (A) Setup for waveguide heating instrument, (B) applicator of waveguide, $(C)$ the diagram in which temperature is as a function of time and (D) resistance time for sample exposed to different input powers.

\section{Cationic surfactants}

One of the less used surfactants in laundry detergents is cationic surfactants due to their tendency to be adsorbed in high rates to and not desorb from - the fabric and the soil because they have both negatively charged surfaces under normal conditions. The mentioned property of adsorption on fabrics is useful in fabric softening. In case these double-long-chain cationic surfactants are combined with anionic surfactants, they would also highly interact with the anionic surfactants which give rise to form insoluble ion pairs and negative results on overall detergency. ${ }^{12}$

\section{Amphoteric surfactant}

Amphoteric surfactant is defined as a surfactant possessing the anionic and cationic hydrophilic group in its structure. This kind of surfactants contains simultaneously hermaphroditic ions which are capable of forming cation or anion based on the ambient conditions such as $\mathrm{pH}$ changes. In general, the main cationic part is an amine salt or a quaternary ammonium hydrophilic group. The anionic part generally contains a carboxylate, sulfonate, phosphate hydrophilic group. Amphoteric surfactants generally are classified into two types: $\mathrm{pH}$-sensitive surfactants and non-ph-sensitive surfactants. The aqueous solution of former has different dissociation degrees in different $\mathrm{pH}$ values. When it is alkaline, it exhibits anionic surfactants agent properties while if it is acidic, it exhibits cationic surfactant properties and upon being neutral, it shows non-ionic surfactant properties. This kind of surfactants has isoelectric point which is a point of the cationic type and anionic type. At this point, the amino acid type amphoteric surfactant precipitates. Other types of amphoteric surfactants such as $\mathrm{N}$ - alkyl betaine type and hydroxyimidazoline shows cationic characteristic based on acidicity. Sulfonic acid type betaine and phosphonyl group betaine are other examples of amphoteric surfactants which significantly used in shampoos; at all ranges of $\mathrm{pH}$ values, they exhibit anionic properties. The lecithin which is contained in egg yolk, is the only ionic surfactant that can be used in the food industry and is almost insoluble in water with excellent emulsifying properties of oil. Amphoteric surfactants generally have antibacterial properties, low toxicity, excellent resistance to hard water, and excellent compatibility with various kinds of surfactants.

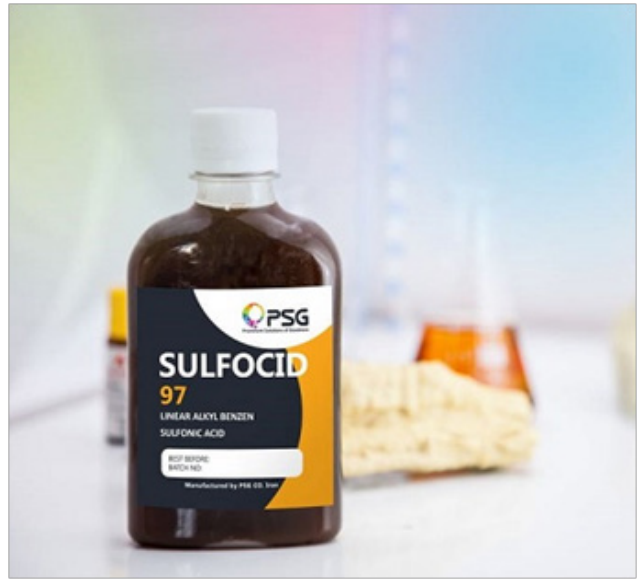

Figure 3 LABS produced in Padideh Shimi Gharb Industrial Company.

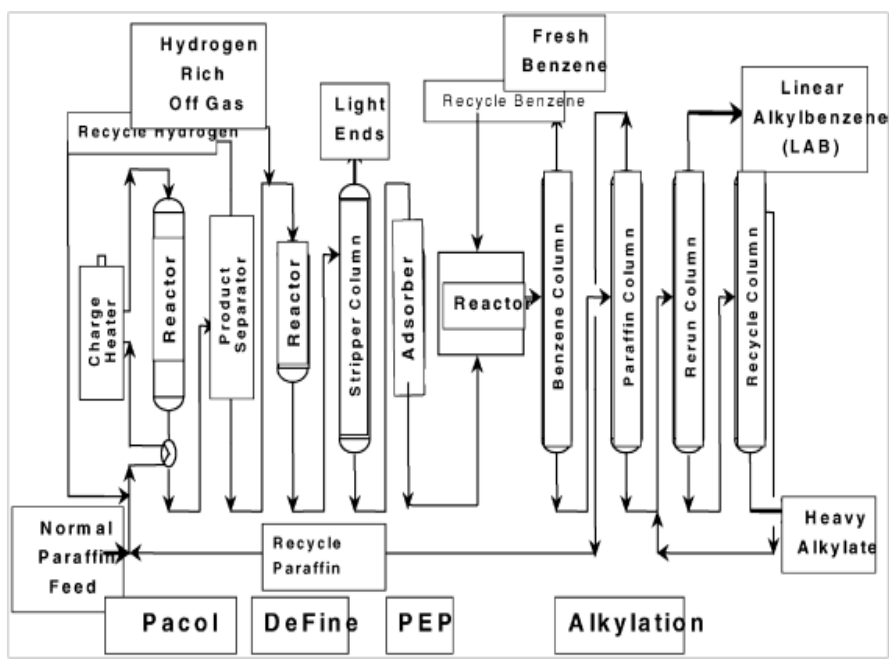

Figure 4 Schematic illustration of the LAB production from normal paraffin. 


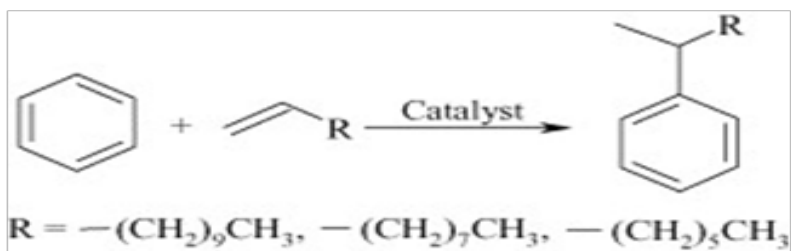

Figure 5 Catalytic synthesis of the LAB using AIMCM-4I/Beta zeolite composite as a catalyst.

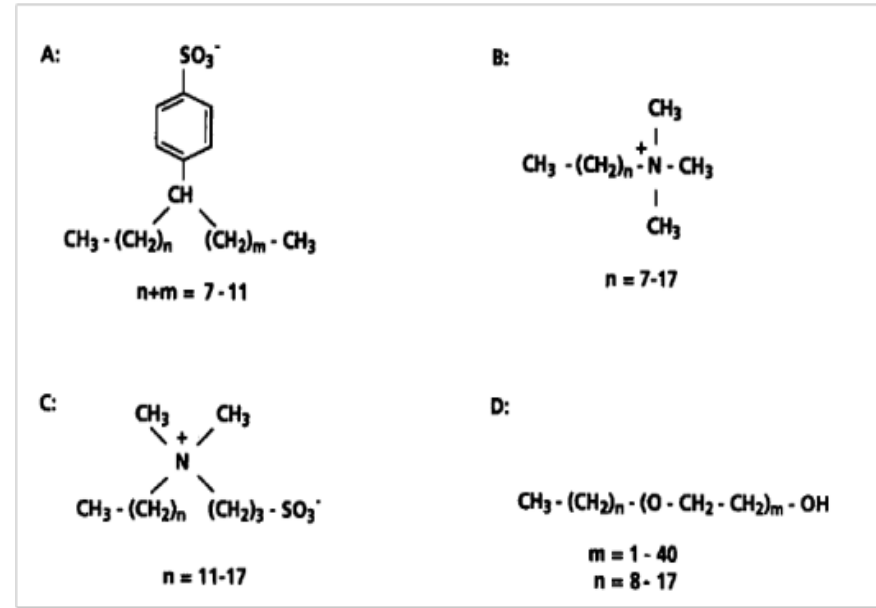

Figure 6 Structures of surfactants as a whole. (A) LABS (Anionic), (B) alkyltrimethylammonium chloride (cationic), (C) alkylsulfobetaine (amphoteric or zwitterion) and (D) alkylpolyoxyethylene ether (nonionic).

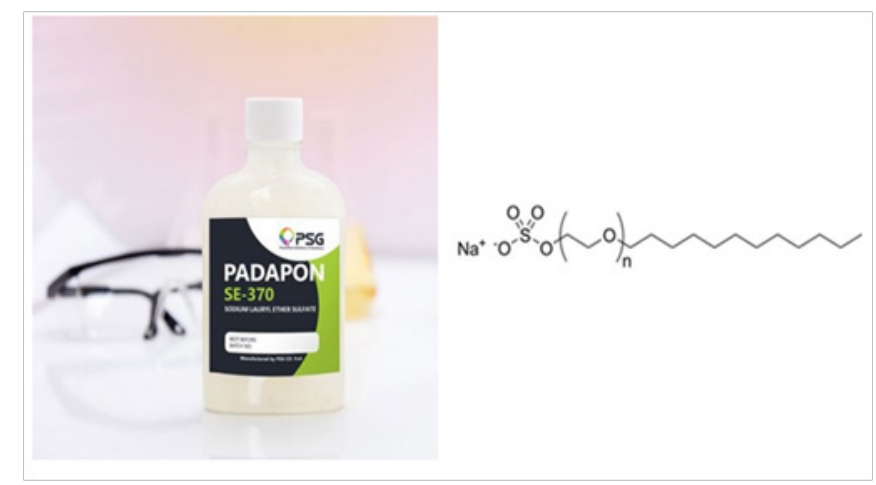

Figure 7 SLES produced in Padideh Shimi Gharb Industrial Company.

Table 2 Activity of the composite material in benzene alkylation with different olefins

\begin{tabular}{lll}
\hline Alkenes & $\begin{array}{l}\text { Alkene con } \\
\text { version (wt. \%) }\end{array}$ & $\begin{array}{l}\text { 2-All-yl benzene } \\
\text { selectivity (o/o) }\end{array}$ \\
\hline I-Dodecene & 48 & 76 \\
I-Decene & 51 & 73 \\
I-Octene & 57 & 69 \\
\hline
\end{tabular}

Hence, they have various applications in detergent industry such as powdered and liquid cleaning agents and shampoos. Another example of amphoteric surfactants is the quaternized fatty acid amides glycine possessing mild properties and almost no irritating effect and as a result it can be used in baby shampoos. One of the well-known foaming agents of shampoo powder is lauryllactam imidazolium salts. Another most used amphoteric surfactant is the amido propyl betaine contained in coconut and has the ability of using in mild shampoos and skin cleansers. Amphoteric surfactants generally are rarely used alone and are often used with fatty alcohol sulfates. This combination gives rise to improve the solubility, increase the viscosity and the foam stability reduce and the irritation property. Amphoteric surfactants also have ability to be used in other applications such as metal rust agent and the antistatic agents of synthetic fiber. Because of the high cost, it applications are subject to certain restrictions. In recent years, amphoteric surfactants have drawn significant attention and as a result have had rapid development. Although it's high price could be considered as a disadvantage, it's numerous advantages which mentioned previously and it's application in tremendous industries is sufficient to compensate for the defects of high price Figure $8 .{ }^{13}$<smiles>CCCCCCCCCCCC[N+](C)(C)CC(=O)O</smiles><smiles>C[N+](C)(CC(=O)O)CC(=O)OC(CC(=O)O)(C(=O)O)C(=O)O</smiles><smiles>C[N+](C)(C)CC(=O)O</smiles>

Lauryl betaine betaine group

Figure 8 Examples of Amphoteric surfactants.

\section{Non-ionic surfactants}

Another group of surfactants which are mostly used in detergents are non-ionic surfactants. Some of the well-known non-ionic surfactants by far are the alcohol ethoxylates (AE) while other groups like alcohol alkoxylates (EO/PO adducts), fatty acid alkanolamides, alkylamine oxides and alkyl polyglucosides (APG) do not play a key role. Because of their voluntary or legal limitations of their appliction, at present, alkylphenol ethoxylates (APE) are only of restricted importance for cleaning detergents. ${ }^{14}$ Ecotoxicological properties of the anionic and non-ionic surfactants typically that are applied in detergents, are in a comparable range. Although their toxicity have been investigated about fish, daphniae and algae which in general is between 1 and $10 \mathrm{mg} / 1$ (LC/EC50), algal toxicity often is believed to be the most sensitive endpoint. In non-ionic surfactants generally the bacterial toxicity is very low, as a result their inhibitory effects to the bacterial biocenosis in wastewater treatment plant are rather improbable. It is noteworthy that the aquatic toxicity of non-ionic surfactants possesses some general rules, so that with the increase in alkyl chain length and hydrophobicity of the molecule the toxicity increases, while the influence of the poly (ethoxylate) chain length is not of prime importance except for long-chain ethoxylates which exhibits a highly reduced ecotoxicity. ${ }^{15}$

\section{Acknowledgments}

The authors gratefully acknowledge the financial support from the Padideh Shimi Gharb Industrial Company.

\section{Conflicts of interest}

The author declares there is no conflict of interest.

\section{References}

1. F Friedli. Detergency of specialty surfactants, CRC Press. Taylor \& Francis. 2001. p. 302.

2. Augustin, Schonfeldt Nikolaus. Aqueous detergent-inorganic builder concentrates. U.S. Patent No. 3,350,319. 31. 1967. 
3. O’brien, Thomas P, Lawrence Benjamin. Liquid detergent composition. U.S. Patent No. 4,268,406. 1981.

4. Wertz, Jean-Luc HM, Pierre CE Goffinet. Near-neutral pH detergents containing anionic surfactant, cosurfactant and fatty acid. U.S. Patent No. 4,561,998. 31 Dec. 1985. Hinton, Gerald Thomas. "Detergent." U.S. Patent No. 6,465,413. 15. 2002

5. J Macias-Zamora, N Ramırez-Alvarez. Tracing sewage pollution using linear alkylbenzenes (LABs) in surface sediments at the south end of the Southern California Bight. Environmental Pollution. 2004;130:229-238.

6. MY Sandhu, FS Saleh, S Afridi, et al. The process for making low density LAS surfactant detergent agglomerates using microwave heating. Powder technology. 2018;326:32-36.

7. JA Kocal, BV Vora, T Imai. Production of linear alkylbenzenes. Applied Catalysis A: General. 2001;221(1-2):295-301.

8. Bordoloi A, Devassy BM, Niphadkar P, et al. Shape selective synthesis of long-chain linear alkyl benzene (LAB) with AlMCM-41/Beta zeolite composite catalyst. Journal of Molecular Catalysis A: Chemical. 2006;253(1-2):239-244.
9. Tolls J, Kloepper-Sams P, Sijm DT. Surfactant bioconcentration-a critical review. Chemosphere. 1994;29(4):693-717.

10. I Johansson, P Somasundaran. Handbook for Cleaning/decontamination of Surfaces 1st edn. Elsevier. 2007. p. 992.

11. K De Clerck, H Demeyere, R Labeque, et al. Laundry Cleaning of Textiles, Handbook for cleaning/decontamination of surfaces. 2007. p. 57

12. EG Lomax. Amphoteric surfactants. CRC Press. 1996.

13. MJ Schick. Nonionic surfactants: physical chemistry. CRC Press. 1987.

14. I. Kralova, J. Sjöblom. Surfactants used in food industry: a review. Journal of Dispersion Science and Technology. 2009;30(9):1363-1383. 